University of Nebraska - Lincoln

DigitalCommons@University of Nebraska - Lincoln

USDA National Wildlife Research Center - Staff Publications
U.S. Department of Agriculture: Animal and Plant Health Inspection Service

2019

\title{
The conundrum of agenda-driven science in conservation
}

\author{
M. Zachariah Peery \\ University of Wisconsin-Madison, mpeery@wisc.edu \\ Gavin M. Jones \\ University of Wisconsin-Madison \\ R. J. Gutierrez \\ University of Wisconsin-Madison \\ Steve M. Redpath \\ University of Aberdeen \\ Alan B. Franklin \\ USDA National Wildlife Research Center
}

See next page for additional authors

Follow this and additional works at: https://digitalcommons.unl.edu/icwdm_usdanwrc

Part of the Life Sciences Commons

Peery, M. Zachariah; Jones, Gavin M.; Gutierrez, R. J.; Redpath, Steve M.; Franklin, Alan B.; Simberloff, Daniel; Turner, Monica G.; Radeloff, Volker C.; and White, Gary C., "The conundrum of agenda-driven science in conservation" (2019). USDA National Wildlife Research Center - Staff Publications. 2229. https://digitalcommons.unl.edu/icwdm_usdanwrc/2229

This Article is brought to you for free and open access by the U.S. Department of Agriculture: Animal and Plant Health Inspection Service at DigitalCommons@University of Nebraska - Lincoln. It has been accepted for inclusion in USDA National Wildlife Research Center - Staff Publications by an authorized administrator of DigitalCommons@University of Nebraska - Lincoln. 


\section{Authors}

M. Zachariah Peery, Gavin M. Jones, R. J. Gutierrez, Steve M. Redpath, Alan B. Franklin, Daniel Simberloff, Monica G. Turner, Volker C. Radeloff, and Gary C. White 


\section{The conundrum of agenda-driven science in conservation}

Conservation biology is a value-laden discipline predicated on conserving biodiversity (Soulé 1985), a mission that does not always sit easily with objective science (Lackey 2007; Pielke 2007; Scott et al. 2007). While some encourage scientists to be responsible advocates for conservation (Garrard et al. 2016), others worry that objectivity in conservation research may suffer (Lackey 2007). At this time, we believe advocacy by scientists is essential for environmental conservation and, indeed, humanity. It is difficult to envision the state of our environment had scientists failed to encourage policy makers and the public to address emerging conservation problems. Nevertheless, conservation scientists must avoid misusing the scientific process to promote specific conservation outcomes (Wilholt 2009); doing so erodes the credibility of science and can produce undesirable consequences (Thomas 1992; Mills 2000; Rohr and McCoy 2010). We consider intentionally engaging in activities outside of professional norms to promote desired outcomes, as part of either the production or dissemination of science, to constitute "agenda-driven science". The issue of advocacy-related bias in conservation science merits renewed discussion because conservation conflicts in an increasingly polarized world might tempt some to engage in agenda-driven science to "win" a conflict (Redpath et al. 2015; Kareiva et al. 2018).

Agenda-driven science can take many forms (Table 1). Concealing conflicts of interest when publishing may indicate that scientists are beholden to parties with a vested interest in results (Rohr and McCoy 2010). The intentional misuse of data, misrepresentation of literature, and misinterpretation of results in a manner favorable to one's conservation objectives are also clear manifestations of agendadriven science (Wilhere 2012). While peer review is the bedrock of science, it can be imperfect and does not always purge poor-quality, agenda-driven science from 
Table 1. Elements of agenda-driven science and some examples of activities outside of scientific norms that may be symptomatic of agenda-driven science

\section{Elements of agenda-driven science}

Undeclared conflicts of interest

Inappropriate use of data and literature

(n)

Drawing unsupported conclusions

Inappropriate use of social media and reliance on quasi-scientific outlets

Inappropriate professional behavior

\section{Activities symptomatic of agenda-driven science}

Failure to disclose funding sources that might benefit from a specific scientific result

Failure to disclose involvement in litigation related to a study

Selective use of data in support of hypotheses

Publishing incomplete or unvetted data

Selectively referencing literature to support hypotheses

Emphasizing certainty and simplicity over uncertainty and complexity

Publishing in journals with lax peer review

Conducting scientific reviews of papers outside of the peer-review process

Pressuring other scientists to retract published papers

Conducting biased reviews of articles

Obtaining other scientists' data through the Freedom of Information Act without seeking collaboration publication and public-policy debates. Further, biased peer review can lead to papers being accepted or rejected because of their perceived conservation implications rather than their scientific merit (Hilborn 2006; Kareiva et al. 2018), such as when Vellend et al. (2013) demonstrated no net biodiversity loss at local scales but a reviewer recommended the paper be rejected over fears that its results could undercut conservation (see Vellend [2018] for details). Importantly, the proliferation of journals with less rigorous peer review increases opportunities to disseminate agenda-driven science (Bohannon 2013). Intimidation or pressuring of scientists, particularly junior scientists, to suppress research is symptomatic of agenda-driven science - as occurred when senior colleagues of Donato et al. (2006) attempted to suppress their study showing negative environmental impacts of salvage logging (Donato et al. 2006; see Harden [2006] for details).

Scientists also play an increasingly important role in communicating conservation issues to the public, with the proliferation of social media, including blogs, and online press outlets expanding opportunities to disseminate science. However, attempts to adjudicate scientific debates in the public sphere by, for example, posting reviews of scientific articles on blogs without the oversight of peer review and customary rebuttals may lead to greater uncertainty and is unlikely to resolve conservation conflicts (Harvey et al. 2018). Such media outlets greatly influence public opinion and policy, and have been used effectively to stoke doubt about the reality of climate change and the dangers of pesticides (Oreskes and Conway 2010).

Agenda-driven science poses a conundrum to conservation because, as defined here, it implies intent, which is difficult to demonstrate. Each of the potential elements of agenda-driven science described in Table 1 may emerge for reasons other than the intentional misuse of science. A poor analysis that supports a desired conservation outcome may be an honest mistake. Moreover, disagreements about scientific conclusions do not necessarily indicate agenda-driven science; they are both commonplace among well-intentioned scientists and an integral part of the scientific process. However, the specter of agendadriven science cannot be ignored when such activities co-occur with conflicts of interest and information campaigns intended to marginalize competing studies outside of the peer-review process. We therefore suggest that it is the cumulative frequency and broader patterns of behaviors outside of scientific norms that indicate agenda-driven science. Even so, assessing when scientific activities "cross the line" is subjective and will be open to interpretation. Recently, several authors of this letter have been involved in a scientific controversy involving forest management and the conservation of spotted owls (Strix occidentalis) in California, elements of which we believe provide an example of this conundrum (see WebPanel 1).

How then should scientists handle the conundrum of agenda-driven science and minimize its impacts on conservation outcomes? We suggest that increased discussion among conservation scientists is needed to help understand how values can lead to biases and ensure that we as a community conduct objective research and stay true to findings in communications with the public. For instance, as part of their graduate education, tomorrow's scientists could benefit from improved training in scientific ethics and communication to avoid engaging in agenda-driven science and to assist the public in distinguishing between rigorous peer-reviewed science and unmoderated scientific debates. Also needed are broadly accepted tools and procedures for recognizing and responding to agenda-driven science. Journal editors and peer reviewers play a key role in guarding against bias in published science but increased vigilance for signs of an intention to influence policy is also needed. Greater disclosure of personal values (as is the case in other scientific disciplines) as well as conflicts of interest (such as litigation activities and consulting for litigants) would facilitate enhanced scrutiny and awareness within the peer-review process. We also encourage professional societies to combat proactively the spread of misinformation to ensure that agenda-driven science does 
not discredit objective science and negatively influence conservation outcomes. Finally, the fostering of a diverse scientific community with a range of values will help maintain objectivity beyond what is possible for individual scientists (Longino 1990). We hope that strategies such as these will help conservation scientists avoid adopting the tactics of those denying the reality of environmental impacts (Oreskes and Conway 2010) we must be the gatekeepers of our own integrity.

\section{Zachariah Peery ${ }^{1 *}$, Gavin M Jones ${ }^{1}$, RJ Gutiérrez ${ }^{1}$, Steve M Redpath ${ }^{2}$, Alan B Franklin ${ }^{3}$, Daniel Simberloff ${ }^{4}$, Monica G Turner ${ }^{1}$, Volker C Radeloff ${ }^{1}$, and Gary C White \\ ${ }^{1}$ University of Wisconsin, Madison, WI*(mpeery@wisc.edu); ${ }^{2}$ University of Aberdeen, Aberdeen, UK; ${ }^{3} U S D A$ \\ National Wildlife Research Center, Fort Collins, CO; ${ }^{4}$ University of Tennessee, \\ Knoxville, TN; ${ }^{5}$ Colorado State \\ University, Fort Collins, CO}

Bohannon J. 2013. Who's afraid of peer review? Science 342: 60-65.

Donato DC, Fontaine JB, Campbell JL, et al. 2006. Post-wildfire logging hinders regeneration and increases fire risk. Science 311: 352.

Garrard GE, Fidler F, Wintle BC, et al. 2016. Beyond advocacy: making space for conservation scientists in public debate. Conserv Lett 9: 208-12.

Harden B. 2006. In fire's wake, logging study inflames debate: university study challenges cutting of burnt timber. The Washington Post. Feb 27.

Harvey JA, Van Den Berg D, Ellers J, et al. 2018. Internet blogs, polar bears, and climate-change denial by proxy. BioScience 68: 281-87.

Hilborn R. 2006. Faith-based fisheries. Fisheries 31: 554-56.

Kareiva P, Marvier M, and Silliman B (Eds). 2018. Effective conservation science: data not dogma. Oxford, UK: Oxford University Press.

Lackey RT. 2007. Science, scientists, and policy advocacy. Conserv Biol 21: 12-17.

Longino HE. 1990. Science as social knowledge: values and objectivity in scientific inquiry. Princeton, NJ: Princeton University Press.
Mills TJ. 2000. Position advocacy by scientists risks scientific credibility and may be unethical. Northwest Sci 74: 165-68.

Oreskes N and Conway EM. 2010. Defeating the merchants of doubt. Nature 465: 686-87.

Pielke Jr RA. 2007. The honest broker. Cambridge, UK: Cambridge University Press.

Redpath S, Young J, Wood K, and Gutiérrez RJ. 2015. Conflicts in conservation: navigating towards solutions. Cambridge, UK: Cambridge University Press.

Rohr JR and McCoy KA. 2010. Preserving environmental health and scientific credibility: a practical guide to reducing conflicts of interest. Conserv Lett 3: 143-50.

Scott JM, Rachlow JL, Lackey RT, et al. 2007. Policy advocacy in science: prevalence, perspectives, and implications for conservation biologists. Conserv Biol 21: 29-35.

Soulé ME. 1985. What is conservation biology? BioScience 35: 727-34.

Thomas JW. 1992. Forest management approaches on the public's lands: turmoil and transition. Berkeley, CA: The Horace M Albright Lectureship in Conservation.

Vellend M. 2018. Are local losses of biodiversity causing degraded ecosystem function? In: Kareiva P, Marvier M, and Silliman B (Eds). Effective conservation science: data not dogma. Oxford, UK: Oxford University Press.

Vellend M, Baeten L, Myers-Smith IH, et al. 2013. Global meta-analysis reveals no net change in local-scale plant biodiversity over time. P Natl Acad Sci USA 110: 19456-59.

Wilhere GF. 2012. Inadvertent advocacy. Conserv Biol 26: 39-46.

Wilholt T. 2009. Bias and values in scientific research. Stud Hist Philos Sci 40: 92-101.

\section{Supporting Information}

Additional, web-only material may may be found in the online version of this article at http://onlinelibrary.wiley.com/ doi/10.1002/fee.2006/suppinfo 
ted owls are affected by wildfire. If large, severe fires negatively affect spotted owl populations, some argue that shortterm negative effects of fuels reduction treatments on spotted owls may provide long-term benefits by reducing wildfire impacts (Tempel et al. 2015). How owls respond to wildfire also has implications for post-fire management such as salvage logging and tree planting; if spotted owls avoid severely burned forests, an argument could be made that these activities can be implemented with limited adverse impacts to spotted owls. Thus, determining the extent to which severe fire affects spotted owls is key for restoring and managing both "green" and burned forests in a region experiencing rapidly warming and drying climatic conditions (Diffenbaugh et al. 2015; Mann and Gleick 2015; Williams et al. 2015; Crockett and Westerling 2018).

\section{The science of spotted owls and fire}

Spotted owls inhabiting seasonally dry forests are expected to be adapted to disturbance regimes characterized by frequent fires that, historically, were typically of low and moderate severity (Gutiérrez et al. 1995, 2017). This hypothesis is supported by virtually all research thus far published on the response of owls to low- and moderate-severity fires (Bond 2016; Ganey et al. 2017). However, conflicting accounts exist regarding the effects of high-severity fire on spotted owls (Ganey et al. 2017). Several studies from one research group (Lee, Bond, and Hanson; hereafter "LBH") indicate that (1) territory occupancy rates (the fraction of historical territories containing spotted owls at time $t$ ) either are not affected, or are affected to a negligible degree, by high-severity fire (Lee et al. 2012, 2013; Lee and Bond 2015a,b; Hanson et al. 2018); and (2) spotted owls marked with radio-transmitters do not avoid severely burned patches of forest when foraging (Bond et al. 2009, 2016). By contrast, recent studies by four independent research groups (see Table 1 in Ganey et al. 2017) reveal negative effects of large, severe fires on spotted owl populations (Jones et al. 2016; Rockweit et al.
2017) and avoidance of severely burned forests by spotted owls marked with radio-transmitters or GPS tags (Comfort et al. 2016; Jones et al. 2016; Eyes et al. 2017).

Conflicting results may, in part, be attributable to differences in landscape patterns of severe fire among studies. For example, Jones et al. (2016) examined changes in territory occupancy by spotted owls following the $\sim 40,000$-ha King Fire, which was one of the largest and most homogeneously severe forest fire events in recent California history (Stevens et al. 2017). Spatial patterns of severe fire in the larger $(\sim 104,000$ ha) Rim Fire studied by Lee and Bond (2015a) were relatively heterogeneous by comparison, which may have resulted in less or no impact on territory occupancy (Jones et al. 2016; Ganey et al. 2017). Similarly, individual territories in Lee et al. $(2012,2013)$ and Lee and Bond (2015b) may not have experienced the same degree of high severity fire as territories in the Jones et al. (2016) study, although it is difficult to make direct comparisons owing to limited information provided by Lee and co-authors. Nevertheless, it is not unreasonable to expect that varying spatial patterns of severe fire might affect spotted owls differently, and it would not be surprising if some of the differences in results among the aforementioned studies emerged because the studies focused on fires with different characteristics.

Competing findings may also have resulted from differences among studies in methods employed. Studies suggesting negative effects of severe fire on spotted owl populations were based on designs using color-marked individuals, whereas studies that did not report negative effects were based on unmarked individuals. Thus, studies reporting little or no effect on spotted owls often assigned territory occupancy status by means of nocturnal detections of owls (Lee et al. 2012, 2013; Lee and Bond 2015a,b; Hanson et al. 2018). However, wide-ranging nocturnal movements by individual owls can lead to the apparent use of multiple territories (ie the same bird detected in 
several territories that are actually unoccupied), resulting in assignment (false positive) bias that can dramatically inflate occupancy rates (Miller et al. 2011; Sutherland et al. 2013) and mask the effect of fire in unmarked owl populations (Berigan et al. 2018). In contrast, Jones et al. (2016), using data from a long-term demographic study of a marked population of owls, excluded such false positive detections in unoccupied territories and were able to estimate high extinction rates for territories that experienced large $(>50 \%)$ amounts of severe fire. Also using color-marked owls, Rockweit et al. (2017) demonstrated that survival rates of individual owls were lower in landscapes that experienced relatively large amounts of high-severity fire. Thus, occupancy-based studies detected neutral or weak effects of severe fire on unmarked spotted owls (Lee et al. 2012, 2013; Lee and Bond 2015a,b) may not have captured the full demographic impacts of severe fire on their study populations.

Understanding why significant differences in results have occurred among spotted owl-fire studies has major implications for balancing ecosystem restoration and species conservation objectives in dry forest ecosystems. If severe fire negatively affects spotted owls and some studies failed to detect the effects of severe fire because they were conducted on unmarked populations, a logical management implication would be that reducing severe fire could benefit spotted owls. If, however, differences in studies are the result of differences in ecological context, where, for example, severe fire primarily impacts spotted owls when these fires occur in large, homogeneous patches, the calculus becomes considerably complex. Specifically, the benefits of reducing severe fire to owls will depend in part on when, and how frequently, severe fire exceeds some currently unknown threshold size and level of homogeneity. We therefore believe much remains to be learned about wildfire effects on spotted owls and additional study is warranted.
Evidence for agenda-driven science in the spotted owl-wildfire debate?

Despite growing consensus among research groups that severe fire can, in some circumstances, adversely affect spotted owls (Ganey et al. 2017), those studies demonstrating such negative effects have been contested by a single research group (LBH) whose studies suggest severe fire has little or no effect on owls. Members of this research group also advocate that:

"...the federal timber sales program must be ended in order for ecological management of our national forests and other federal forestlands to occur."

-John Muir Project of Earth Island Institute (2014)

"We propose expansion of the National Park Service model of forest management to encompass all California's US Forest Service lands."

-Wild Nature Institute (2019)

Certainly, advocacy in support of these positions could, in some cases, be justified because fuels treatments and salvage logging have the potential to be detrimental to owl habitat and forest ecosystems, respectively (Lindenmayer and Noss 2006; Ganey et al. 2017). However, as detailed below, it is our opinion that LBH appear to have engaged in six activities outside of professional norms in support of their advocacy that promote a narrative that high-severity wildfire does not threaten spotted owls. These apparent activities include: (i) mixing science and litigation without disclosing potential conflicts of interest; (ii) using social media (rather than peer-reviewed journals) to conduct critical scientific reviews of studies that do not support the findings of their own work; (iii) pressuring scientists and graduate students with different research findings to retract their papers or not publish their thesis findings; (iv) conducting erroneous analyses using data they did not collect and with which they were unfamiliar; (v) selectively using data that support their agendas; and (vi) making management recommendations beyond what is reasonably supported by scientific findings. Individually, we consider each of these activities to fall outside of scientific norms. Collectively, however, they may be symptomatic of agenda-driven science involving attempts to understate uncertainty and promote a narrative not fully supported by the scientific literature that aims to influence forest management. As described in the main text of the associated letter, recognizing when scientific activities "cross the line" and enter the realm of agenda-driven science is a "gray area" and is thus subjective. Consequently, we leave it to the reader to decide whether, taken together, these activities constitute agenda-driven science. Following our description of each of the questionable activities exhibited by $\mathrm{LBH}$, we discuss how these six activities can be identified and rebutted in conservation science.

Mixing science and litigation without declaring potential conflicts of interest

Hanson (of LBH) is both a lawyer and a scientist who cites the peer-reviewed publications of LBH in litigation activities opposed to fuels reduction treatments and salvage logging on national forests (eg Earth Island Institute vs US Forest Service 2006). His legal arguments depend on (i) severe wildfire mostly being benign to spotted owls, regardless of scale and extent; and (ii) forest restoration activities posing the primary threat to this species, as he and his colleagues have suggested is the case in many publications (eg Bond 2016; Hanson et al. 2018; Lee 2018). Moreover, Bond and Lee are frequently involved in Hanson's cases as expert witnesses who produce declarations arguing that severe wildfire does not substantially impact spotted owls. And, in some cases, court cases have been decided in favor of the plaintiffs and prevented planned forest management, with judgments citing LBH's studies finding that severe fire is mostly benign to spotted owl habitat (Earth Island Institute vs US Forest Service 2006). Nevertheless, these litigation activities and potential conflicts of interest - are not disclosed in their scientific papers 
(eg Lee and Bond 2015b; Hanson et al. 2018).

While scientists will inevitably be party to ligation for legitimate reasons, science conducted "to prove a point" in support of litigation is antithetical to the scientific process. We agree with others that agenda-driven science is particularly likely to emerge when science is produced to support litigation (Haack 2008). Indeed, the objectives of attorneys (to advocate on behalf of clients) and scientists (to seek truth) are fundamentally different and individuals engaged in both science and litigation are confronted with a substantial conflict of interest (Murphy and Noon 1991; Noon and Murphy 1994). However, if an individual or a group is centrally involved in both the production of science and litigation (as is the case with LBH), it is difficult to know whether the two processes (science and litigation) are independent, or whether the science is produced in order to provide support to an argument (ie an agenda) in the courtroom. For this reason, we suggest that scientific journals make these potential conflicts of interest more transparent by requiring that authors disclose any litigation activities they have been involved in related to the study they seek to publish, which would facilitate greater scrutiny for signs of agenda-driven science.

\section{Inappropriate scientific rebuttal through social and quasi-scientific media}

LBH have engaged in an information campaign via social media and quasi-scientific media outside of the peer-review process to discredit a study published in Frontiers in Ecology and the Environment (hereafter, "Frontiers") that documented effects of a large, severe fire on spotted owls (Jones et al. 2016) (note: several authors of the present letter [Jones, Peery, and Gutiérrez; JPG] were co-authors on Jones et al. 2016). Specifically, members of $\mathrm{LBH}$ posted a scientific review titled "Jones et al. 'Megafire' paper is bad science" as a blog on their website (Wild Nature Institute 2016), with one member posting a similar criticism on social media demanding that Jones and coworkers retract their study (eg Lee 2016). Soon thereafter, the editor of Frontiers informed JPG that a Write Back letter, critical of Jones et al. (2016), had been submitted to Frontiers and that, if the response was accepted, we would be given an opportunity to respond. As this letter has not appeared and we did not receive a request to respond, we can only assume it was rejected for lack of scientific merit. However, shortly after we were informed of the critical response submitted to Frontiers, Bond and Lee posted criticisms similar to those made on the Wild Nature Institute blog to the website PubPeer (Bond and Lee 2016). In addition, members of LBH collaborated with a science writer to produce a misleading article in the quasi-scientific online publication BOOM California, which mistakenly claimed that the effects of severe fire on owls in Jones et al. (2016) were spurious (Khosla 2017). For example, the author inaccurately claimed, among other things, that Jones et al. (2016) misclassified the occupancy status of several spotted owl territories without contacting Jones and coworkers to verify this statement or to obtain their perspective. The author also misrepresented the fact that Bond and Lee's rebuttal (Bond and Lee 2016) was presumably rejected from Frontiers by only stating Lee had "alerted" the editors of Frontiers to the errors in Jones et al. (2016).

The proliferation of social media and other online forums has greatly increased opportunities for scientists to engage in professional networking and share science with their peers. While we applaud and welcome these opportunities, we do not believe the adjudication of scientific debates on social and related media is appropriate. Posting scientific reviews of peer-reviewed papers on social media or blogs, for example, does not allow for customary rebuttals or the oversight of peer review. Nor is it appropriate for a scientist to call for retraction of a peer-reviewed paper on social media without having his/her own arguments for such a retraction peer reviewed. Scientists confronted with agenda-driven science via critical reviews on social media and antagonistic online information campaigns face a quandary. Should they respond and defend their work using similar forums? While we recognize that opinions will vary, we believe that scientific debates are unlikely to be resolved in unmoderated forums. Rather, we suggest the best approach is for scientists who find fault with a published paper to respond in peer-reviewed journal forums where they can present a body of well-supported scientific criticism and to which the criticized authors can also provide their formal responses - all within the context of peer review. The promotion of agenda-driven science via the popular press, however, poses a different dilemma, as the target audience is the general public. Given the importance of public opinion in developing effective conservation policy, responding to agenda-driven science via the popular press may be important. Thus, we suggest that scientists take criticisms leveled in the popular press on a case-by-case basis; when there is a considerable risk that the public is being misinformed, setting the record straight is both justified and essential.

\section{Harassment of scientists publishing competing studies}

Members of LBH and their funders apply pressure to scientists - including graduate students - that have found negative effects of severe wildfire on spotted owls to retract or not publish their scientific papers (eg GM Jones, pers comm; SA Eyes, pers comm). In their correspondence pressuring scientists to do so, members of LBH employ a "strategy of guilt", arguing that results from these studies are being used by natural resource agencies to promote management actions deleterious to conservation of spotted owls, the implication being that the scientist (or graduate student) is contributing to further jeopardy to the owl.

While critique is an essential part of the scientific process and every scientist has the right to question other scientists about their methods or conclusions in a constructive manner, using guilt about how scientific results will be applied to 
conservation is not an appropriate way to resolve conflicts. As scientists, we are obliged to seek the truth and we should not avoid pursuing research simply because someone might misuse it. Moreover, the strategy of guilt is particularly inappropriate when more senior scientists pressure junior scientists, particularly graduate students, into conforming to their own perspective. Graduate students are at a vulnerable career stage, and they are learning to navigate the complex intersections among science, management, and policy. Mentors, institutions, and the broader scientific community should support and defend graduate students and junior scientists whose work is targeted by advocacy groups.

\section{Inappropriate use of other scientists' data}

Many, if not most, of the spotted owlwildfire publications LBH have produced used data they did not collect themselves. Moreover, LBH regularly use the Freedom of Information Act (FOIA) as a mechanism to obtain or try to obtain other researchers' data without seeking collaboration or offering co-authorship (A Franklin, pers comm; D Lesmeister, pers comm; J Keane, pers comm). While open-access data and data sharing are becoming increasingly important in scientific research, we believe that a lack of understanding of the data collected by other scientists has likely led LBH to make analytical errors and draw erroneous inferences about effects of wildfire on spotted owls. For example, the data Lee and Bond (2015b) used to infer high rates of territory occupancy one year after the 2013 Rim Fire had not yet been vetted and contained several hundred errors at the time the data were obtained from US Forest Service biologists (without the consent of the principal investigator; J Keane, pers comm). Further, LBH made no attempt to contact the principal investigator or the biologists who collected the data to detect, understand, or correct data errors (J Keane, pers comm). Hanson et al. (2018) also lacked complete information on spotted owl territory occupan- cy histories when they re-analyzed data collected and published by Jones et al. (2016). For example, Hanson et al. treated one territory ("PLA0065"; a unique code corresponding with USFS-delineated spotted owl management units) as unoccupied both before (2014) and after the King Fire (2015). However, this territory was field-verified shortly before the fire to be occupied by a banded pair of owls that fledged three young in 2014 and went extinct after experiencing high severity fire across $95 \%$ of its area (the burned remains of the banded male were found near the nest site in the spring following the fire). Further, Hanson et al. treated a different territory (PLA0039) as occupied before and after the fire, while in fact this territory became unoccupied after the fire. We surmise this error occurred because LBH misattributed an apparent detection of owls in PLA0039 in 2015 to an adjacent (but spatially overlapping) territory (PLA0080) that was the primary nest/ roost area being used by spotted owls in that year. Therefore, PLA0039 should have been classified as unoccupied post-fire (Berigan et al. 2018). Together, these errors contributed to Hanson et al. (2018) concluding that the 2014 King Fire did not negatively impact spotted owls.

The trend toward open-access data in science has both increased transparency and catalyzed scientific advances. However, messy data are inherent in ecological research and faulty inferences can easily result when data are re-analyzed with little understanding of the data collection process. Thus, we consider the repeated use of other's data without their involvement and without a thorough understanding of those data to be inappropriate in conservation research. Indeed, the "ambiguities" of raw ecological data underscore the importance of pursuing collaborative science as part of resolving conservation conflicts. Politically charged science can also be resolved through independent review mechanisms, such as meta-analysis workshops that include outside scientists (Anderson et al. 1999).

\section{Selective use of data}

Hanson et al. (2018) re-analyzed some data from Jones et al. (2016), wherein Jones et al. reported that extensive severe wildfire can reduce spotted owl territory occupancy. However, Hanson et al. excluded the four most severely burned territories from their analysis (91-99\% of the area within these territories burned at a high severity: PLA0050, PLA0067, PLA0013, and PLA0065). They thereby eliminated the territories most likely to demonstrate severe fire effects. Moreover, all four territories were occupied in the breeding season prior to the King Fire but were unoccupied following the fire (ie they went extinct). Hanson et al.'s justification for excluding these data was that including sites that burned $>80 \%$ at high severity would disrupt their factorial design intended to distinguish between the categorical effects of severe fire ( $20-49 \%$ vs $50-80 \%$ of territory area affected) and salvage logging ( $<5 \%$ vs $\geq 5 \%$ of territory area), because few of these sites experienced $<5 \%$ salvage logging. However, if the objective of a study is to examine an effect, whether it be fire and/ or salvage logging, why exclude data that had potential to test the effect? Rather than treating severe fire and salvage logging as categorical effects, Hanson et al. could simply have treated them as continuous predictors of occupancy. This approach would have circumvented the problem they invoked as justification, and strengthened their ability to detect effects (Cottingham et al. 2005).

Recognizing whether data have been intentionally used in a selective manner is challenging, and may simply be the product of unintentional poor scholarship on the part of a scientist. Without direct evidence of intent, such actions, then, must be considered within the context of a scientist's broader pattern of behavior. For example, does he/she have a conflict of interest that might compel him/her to make such decisions to exclude relevant, indeed critical, data? In light of the difficulties in detecting such biases, we suggest that editors and reviewers be alert to selective use of data when reviewing studies that criticize oth- 
er papers, especially when "re-analyses" of data occur to support such criticism.

\section{Drawing conclusions beyond scientific findings}

Lee (2018) conducted a meta-analysis testing for effects of wildfire on spotted owls across 21 published studies and did not detect a significant overall effect of fire on foraging, demography, or territory occupancy. He concluded that:

"Contrary to current perceptions and recovery efforts for the Spotted Owl, mixed-severity fire does not appear to be a serious threat to owl populations; rather, wildfire has arguably more benefits than costs for Spotted Owls."

Lee's conclusion oversteps his results for three reasons. First, the estimated overall (negative) effect of wildfire on spotted owl territory occupancy was nearly statistically significant at the 0.05 level $(P=0.07)$. Second, meta-analyses that focus on summary effects when among-study variability is high are likely to lead to conclusions that are wrong, perhaps seriously so (Bailar 1997; Borenstein et al. 2009). Thus, even if the negative effect of fire on occupancy had been statistically significant, it would have been difficult or impossible to interpret directly because of high variation in estimated fire effects among studies. Indeed, variability in the estimated effect size of fire on occupancy was extremely high by meta-analytical standards as measured by its $I^{2}$ value (Higgins et al. 2003) of 97.7\% $(P<0.001)$, where generalizations should be avoided when $I^{2}$ values exceed 50-75\% (Higgins and Thompson 2002; Higgins et al. 2003). $I^{2}$ values were nearly as extreme for the other variables examined (demography $=84.0 \%, P<0.001$; foraging $=84.4 \%, P<0.001)$. Moreover, variability in estimated fire effects among studies was greater at burned than unburned territories. This high level of variability betrays generalization, making Lee's conclusion that fire does not threaten owl populations unsubstantiated. Instead, the high variability among studies should have led to the conclusion that effects of wildfire are likely context specific, perhaps related to spatial patterns of burned areas. Third, the conclusion that wildfire does not pose a threat to spotted owls does not take into account that wildfires in many forest ecosystems are predicted to become larger and more severe as the climate changes (Westerling and Bryant 2008; Stephens et al. 2013; Liu et al. 2013; Millar and Stephenson 2015; Abatzoglou and Williams 2016).

Determining whether conclusions and management recommendations that extend beyond the results of a study were made intentionally is challenging, because interpretation of results can be subjective; even when conclusions are unsupported, intent will often be unknown. However, sweeping conclusions that previous studies are in error, and conclusions that emphasize certainty instead of uncertainty and complexity, are potential signs of agenda-driven science.

Whether deliberate or inadvertent, $\mathrm{LBH}$ appear to have engaged in a series of activities, both within and outside of the peer-review process, that have resulted in the under-appreciation of the effects of severe wildfire on spotted owls. This case study underscores the importance of recognizing and understanding how to respond to activities that may be symptomatic of agenda-driven science. In the case of spotted owls, ignoring negative effects of severe wildfire could compromise the ability to conserve this species and restore forest ecosystems that are experiencing increasingly large and severe fires as the climate becomes warmer and drier. Meeting these dual objectives will be complex, but the process is made more complicated and challenging if scientists engage in activities that lead to incorrect scientific narratives rather than collaboratively trying to solve the problem.

\section{Acknowledgements}

The USDA Forest Service, California Department of Fish and Wildlife, and US Fish and Wildlife Service funded the original King Fire study (Jones et al. 2016) discussed herein.
M Zachariah Peery ${ }^{1 *}$, Gavin M Jones ${ }^{1}$, RJ Gutiérrez ${ }^{1}$, Steve M Redpath ${ }^{2}$, Alan B Franklin ${ }^{3}$, Daniel Simberloff ${ }^{4}$, Monica G Turner ${ }^{1}$, Volker C Radeloff ${ }^{1}$, and Gary C White ${ }^{5}$

${ }^{1}$ University of Wisconsin, Madison, WI*(mpeery@wisc.edu); ${ }^{2}$ University of Aberdeen, Aberdeen, UK; ${ }^{3}$ USDA National Wildlife Research Center, Fort Collins, CO; ${ }^{4}$ University of Tennessee, Knoxville, TN; ${ }^{5}$ Colorado State

University, Fort Collins, $\mathrm{CO}$

Abatzoglou JT and Williams AP. 2016. Impact of anthropogenic climate change on wildfire across western US forests. $P$ Natl Acad Sci USA 113: 11770-75.

Ager AA, Finney MA, Kerns BK, and Maffei H. 2007. Modeling wildfire risk to northern spotted owl (Strix occidentalis caurina) habitat in Central Oregon, USA. For Ecol Manage 246: 45-56.

Anderson DR, Burnham KP, Franklin AB, et al. 1999. A protocol for conflict resolution in analyzing empirical data related to natural resource controversies. Wildl Soc Bull 27: 1050-58.

Bailar J. 1997. The promise and problems of meta-analysis. N Engl J Med 337: 559-60.

Berigan WJ, Jones GM, Whitmore SA, et al. 2018. Cryptic wide-ranging movements lead to upwardly-biased occupancy in a territorial species. J Appl Ecol; doi. org/10.1111/1365-2664.13265.

Bond ML. 2016. The heat is on: spotted owls and wildfire. Earth Syst Environ Sci Ref Modul; doi.org/10.1016/B978-0-12409548-9.10014-4.

Bond ML, Bradley C, and Lee DE. 2016. Foraging habitat selection by California spotted owls after fire. J Wildl Manage 80: 1290-300.

Bond ML and Lee DE. 2016. Megafires are not a threat - response to Jones et al. https:// pubpeer.com/publications/CF77DE0 1 $24123971 \mathrm{E} 348609 \mathrm{C} 55 \mathrm{~F} 65 \mathrm{C}$ \#f 108568. Viewed 6 Sep 2018.

Bond ML, Lee DE, Siegel RB, and Ward JP. 2009. Habitat use and selection by California spotted owls in a postfire landscape. $J$ Wildl Manage 73: 1116-24.

Borenstein M, Hedges LV, Higgins JPT, and Rothstein HR. 2009. Introduction to meta-analysis. West Sussex, UK: John Wiley and Sons.

Calkin DE, Gebert KM, Jones JG, and Neil- 
son RP. 2005. Forest Service large fire area burned and suppression expenditure trends, 1970-2002. J For 103: 179-83.

Collins BM, Fry DL, Lydersen JM, et al. 2017. Impacts of different land management histories on forest change. Ecol Appl 27: 2475-86.

Collins BM, Stephens SL, Moghaddas JJ, and Battles JJ. 2010. Challenges and approaches in planning fuel treatments across fire-excluded forested landscapes. J For 108: 24-31.

Comfort EJ, Clark DA, Anthony RG, et al. 2016. Quantifying edges as gradients at multiple scales improves habitat selection models for northern spotted owl. Landsc Ecol 31: 1227-40.

Cottingham KL, Lennon JT, Brown BL, et al. 2005. Knowing when to draw the line: designing more informative ecological experiments. Front Ecol Environ 3: 145-52.

Crockett JL and Westerling AL. 2018. Greater temperature and precipitation extremes intensify Western US droughts, wildfire severity, and Sierra Nevada tree mortality. J Clim 31: 341-54.

Diffenbaugh NS, Swain DL, and Touma D. 2015. Anthropogenic warming has increased drought risk in California. $P$ Natl Acad Sci USA 112: 3931-36.

Earth Island Institute vs US Forest Service. 2006. 442 F.3d 1147. United States Court Appeals, Ninth Circuit.

Eyes SA, Roberts SL, and Johnson MD. 2017. California spotted owl (Strix occidentalis occidentalis) habitat use patterns in a burned landscape. Condor 119: $1-15$.

Ganey JL, Wan HY, Cushman SA, and Vojta CD. 2017. Conflicting perspectives on spotted owls, wildfire, and forest restoration. Fire Ecol 13: 146-65.

Gutiérrez RJ. 2015. The spotted owl and conservation of old-growth forests in western North America. In: Redpath SM, Gutiérrez RJ, Wood K, and Young JC (Eds). Conflicts in conservation: navigating towards solutions. Cambridge, UK: Cambridge University Press.

Gutiérrez RJ, Franklin AB, and Lahaye WS. 1995. Spotted owl (Strix occidentalis). In: Poole A and Gill F (Eds). The birds of North America No. 179: life histories for the 21st century. Washington, DC: The Philadelphia Academy of Sciences; The American Ornithologists' Union.
Gutiérrez RJ, Tempel DJ, and Peery MZ. 2017. The biology of the California spotted owl. In: Gutiérrez RJ, Manley PN, Stine PA (Eds). The California spotted owl: current state of knowledge. Albany, CA: PSWGTR-254.

Haack S. 2008. What's wrong with litigation-driven science? An essay in legal epistemology. Seton Hall Law Rev 38: 1053-83.

Hagmann RK, Johnson DL, and Johnson KN. 2017. Historical and current forest conditions in the range of the northern spotted owl in south central Oregon, USA. For Ecol Manage 389: 374-85.

Hanson CT, Bond ML, and Lee DE. 2018. Effects of post-fire logging on California spotted owl occupancy. Nat Conserv 24: 93-105.

Higgins JPT and Thompson SG. 2002. Quantifying heterogeneity in a meta-analysis. Stat Med 21: 1539-58.

Higgins JPT, Thompson SG, Deeks JJ, and Altman DG. 2003. Measuring inconsistency in meta-analyses. $B M J \mathrm{Br} M e d J$ 327: 557-60.

John Muir Project of Earth Island Institute. 2014. About us. http://johnmuirproject. org/about-us. Viewed 8 Feb 2018.

Jones GM, Gutiérrez RJ, Tempel DJ, et al. 2016. Megafires: an emerging threat to old-forest species. Front Ecol Environ 14: 300-06.

Khosla M. 2017. Heating up: California spotted owls and wildfire. https://boomcalifornia. com/2017/10/20/heating-up-california-spotted-owls-and-wildfire/. Viewed 12 Feb 2018.

Lee DE. 2016. Comment on: Megafires: an emerging threat to old-forest species. https://www.researchgate.net/ publication/305765977_Megafires_an_ emerging_threat_to_old-forest_species/ comments. Viewed 12 Feb 2018.

Lee DE. 2018. Spotted owls and forest fire: a systematic review and meta-analysis of the evidence. Ecosphere 9: e02354.

Lee DE and Bond ML. 2015a. Previous year's reproductive state affects spotted owl site occupancy and reproduction responses to natural and anthropogenic disturbances. Condor Ornithol Appl 117: 307-19.

Lee DE and Bond ML. 2015b. Occupancy of California spotted owl sites following a large fire in the Sierra Nevada, California. Condor 117: 228-36.
Lee DE, Bond ML, Borchert MI, and Tanner R. 2013. Influence of fire and salvage logging on site occupancy of spotted owls in the San Bernardino and San Jacinto mountains of Southern California. J Wildl Manage 77: 1327-41.

Lee DE, Bond ML, and Siegel RB. 2012. Dynamics of breeding-season site occupancy of the California spotted owl in burned forests. Condor 114: 792-802.

Lehmkuhl J, Gaines W, Peterson DW, et al. 2015. Silviculture and monitoring guidelines for integrating restoration of dry mixed-conifer forest and spotted owl habitat management in the eastern Cascade Range. PNW-GTR-915.

Lehmkuhl JF, Kennedy M, Ford ED, et al. 2007. Seeing the forest for the fuel: integrating ecological values and fuels management. For Ecol Manage 246: 73-80.

Lindenmayer DB and Noss RF. 2006. Salvage logging, ecosystem processes, and biodiversity conservation. Conserv Biol 20: 949-58.

Liu Y, Goodrick SL, and Stanturf JA. 2013. Future US wildfire potential trends projected using a dynamically downscaled climate change scenario. For Ecol Manage 294: 120-35.

Mann ME and Gleick PH. 2015. Climate change and California drought in the 21st century. P Natl Acad Sci USA 112: 385859.

Millar CI and Stephenson NL. 2015. Temperate forest health in an era of emerging megadisturbance. Science 349: 823-26.

Miller DA, Nichols JD, McClintock BT, et al. 2011. Improving occupancy estimation when two types of observational error occur: non-detection and species misidentification. Ecology 92: 1422-28.

Murphy DD and Noon BD. 1991. Coping with uncertainty in wildlife biology. $J$ Wildl Manage 55: 773-82.

Noon BR and Murphy DD. 1994. Management of the spotted owl: the interaction of science, policy, politics, and litigation. In: Meffe G and Carroll CR (Eds). Principles of conservation biology. Sunderland, MA: Sinauer Associates.

North MP, Stephens SL, Collins BM, et al. 2015. Reform forest fire management: agency incentives undermine policy effectiveness. Science 349: 1280-81.

Rockweit JT, Franklin AB, and Carlson PC. 2017. Differential impacts of wildfire on 
the population dynamics of an old-forest species. Ecology 98: 1574-82.

Simberloff D. 1987. The spotted owl fracas: mixing academic, applied, and political ecology. Ecology 68: 766-72.

Steel ZL, Safford HD, and Viers JH. 2015. The fire frequency-severity relationship and the legacy of fire suppression in California forests. Ecosphere 6: 8.

Stephens SL, Agee JK, Fulé PZ, et al. 2013. Managing forests and fire in changing climates. Science 342: 41-42.

Stephens SL, Bigelow SW, Burnett RD, et al. 2014. California spotted owl, songbird, and small mammal responses to landscape fuel treatments. BioScience 64: 893-906.

Stevens JT, Collins BM, Miller JD, et al. 2017. Changing spatial patterns of stand-replacing fire in California conifer forests. For Ecol Manage 406: 28-36.

Sutherland CA, Elston DAB, and Lambin XA. 2013. Accounting for false positive detection error induced by transient individuals. Wildl Res 40: 490-98.

Tempel DJ, Gutiérrez RJ, Battles JJ, et al. 2015. Evaluating short- and long-term impacts of fuels treatments and wildfire on an old-forest species. Ecosphere 6: art261.

Tempel DJ, Gutiérrez RJ, Whitmore SA, et al. 2014. Effects of forest management on California spotted owls: implications for reducing wildfire risk in fire-prone forests. Ecol Appl 24: 2089-106.

Tempel DJ, Keane JJ, Gutiérrez RJ, et al. 2016. Meta-analysis of California spotted owl (Strix occidentalis occidentalis) territory occupancy in the Sierra Nevada: habitat associations and their implications for forest management. Condor 118: 747-65.

Westerling AL and Bryant BP. 2008. Climate change and wildfire in California. Clim Change 87 (Supplement 1): 231-49.

Wild Nature Institute. 2016. Jones et al. "Megafire" paper is bad science. www.wildnatureinstitute.org/blog/jones-et-al-megafire-paper-is-bad-science. Viewed 12 Feb 2018.

Wild Nature Institute. 2019. Forests for everyone (44E1). https://www.wildnatureinstitute.org/forests-for-everyone.html. Viewed 11 Jan 2019.

Williams AP, Seager R, Abatzoglou J, et al. 2015. Contribution of anthropogenic warming to California drought during 2012-2014. Geophys Res Lett 42: 6819-28. 